\title{
Foreword:
}

\section{Advances in Materials Manufacturing}

Advanced materials manufacturing plays a vital role in the innovation of novel technologies as well as economic and scientific leadership internationally. To better share knowledge on the state-of-the-art of recent advances in materials manufacturing, the first international symposium on "Advances in Materials Manufacturing" at the COM 2014 Conference of Metallurgists, Canadian Institute of Mining, Metallurgy and Petroleum (CIM), was held from 28 September to 1 October, 2014 in Vancouver, British Columbia, Canada.

The symposium focused on the latest developments in manufacturing and processing of conventional and advanced materials. The scope included additive manufacturing, welding and joining (laser welding, hybrid laser-arc welding, electron beam, friction stir welding, linear friction, soldering, brazing, diffusion bonding, adhesive bonding), casting, laser and laser-assisted materials processing, powder metallurgy, spark plasma sintering, forming, hot isostatic pressing, and other advanced materials manufacturing and processing technologies.

During the three-day symposium, scientists and researchers from 13 countries attended and presented more than 30 outstanding technical talks. Select works are now being brought forward as a part of a special issue of this Metallurgical and Materials Transactions $B$ journal. We are very grateful to the authors for participating in the symposium. Also, the assistance of key readers and reviewers of MMT-B during the publication process is gratefully acknowledged. We hope you will enjoy the following papers as we continue sharing the knowledge presented at the symposium. We also hope to see you at future Advances in Materials Manufacturing symposia at COM conferences to be held in Canada!

Symposium Organizers:

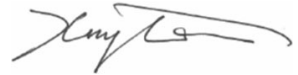

Xinjin Cao, PhD, PEng, FCIM

National Research Council Canada - Aerospace, Ottawa, Canada E-Mail: xinjin.cao@cnrc-nrc.gc.ca

Cusas O.chle
Lukas Bichler, PhD, PEng

